\title{
Function of L-Pipecolic Acid as Compatible Solute in Corynebacterium glutamicum as Basis for Its Production Under Hyperosmolar Conditions
}

\author{
Fernando Pérez-García, Luciana F. Brito and Volker F. Wendisch* \\ Genetics of Prokaryotes, Faculty of Biology - CeBiTec, Bielefeld University, Bielefeld, Germany
}

OPEN ACCESS

Edited by:

Peter Neubauer,

Technische Universität Berlin,

Germany

Reviewed by:

Xiaoyuan Wang,

Jiangnan University, China

Marco Oldiges,

Forschungszentrum Jülich, Helmholtz Association of German Research

Centers (HZ), Germany

${ }^{*}$ Correspondence:

Volker F. Wendisch

volker.wendisch@uni-bielefeld.de

Specialty section:

This article was submitted to Microbiotechnology, Ecotoxicology

and Bioremediation,

a section of the journal

Frontiers in Microbiology

Received: 13 November 2018 Accepted: 08 February 2019

Published: 25 February 2019

Citation:

Pérez-García F, Brito LF and Wendisch VF (2019) Function of L-Pipecolic Acid as Compatible Solute in Corynebacterium glutamicum as Basis for lts

Production Under Hyperosmolar Conditions. Front. Microbiol. 10:340.

doi: 10.3389/fmich.2019.00340
Pipecolic acid or L-PA is a cyclic amino acid derived from L-lysine which has gained interest in the recent years within the pharmaceutical and chemical industries. L-PA can be produced efficiently using recombinant Corynebacterium glutamicum strains by expanding the natural L-lysine biosynthetic pathway. L-PA is a six-membered ring homolog of the five-membered ring amino acid L-proline, which serves as compatible solute in C. glutamicum.

Here, we show that de novo synthesized or externally added L-PA partially is beneficial for growth under hyper-osmotic stress conditions. C. glutamicum cells accumulated L-PA under elevated osmotic pressure and released it after an osmotic down shock. In the absence of the mechanosensitive channel YggB intracellular L-PA concentrations increased and its release after osmotic down shock was slower. The proline permease ProP was identified as a candidate L-PA uptake system since RNAseq analysis revealed increased proP RNA levels upon L-PA production. Under hyper-osmotic conditions, a $\triangle$ proP strain showed similar growth behavior than the parent strain when L-proline was added externally. By contrast, the growth impairment of the $\triangle$ proP strain under hyper-osmotic conditions could not be alleviated by addition of L-PA unless proP was expressed from a plasmid. This is commensurate with the view that L-proline can be imported into the C. glutamicum cell by ProP and other transporters such as EctP and PutP, while ProP appears of major importance for L-PA uptake under hyper-osmotic stress conditions.

Keywords: pipecolic acid, osmo regulation, compatible solute, proline, Corynebacterium glutamicum, RNAseq analysis, solute export, solute uptake

\section{INTRODUCTION}

In nature, all living organisms must respond to environmental fluctuations to survive. For example, bacteria have developed defense mechanisms for hyper- and hypo-osmotic external conditions to maintain cell viability including the de novo synthesis or uptake of osmo compatible solutes such as betaines. Since plants also contain these osmo compatible solutes, they are commonly present in production media and, thus, relevant for biotechnological fermentations (Farwick et al., 1995). The industrial workhorse Corynebacterium glutamicum disposes of mechanosensitive channels (MSCs) which perform as emergency release valves (Ruffert et al., 1999). After an osmotic downshift 
and to avoid cell lysis, MSCs are immediately activated by membrane turgor pressure to release solutes and to decrease in the internal osmolality (Ruffert et al., 1997; Morbach and Krämer, 2003). C. glutamicum can synthesize proline, glutamine, and trehalose and use them as compatible solutes, whereas it cannot synthesize ectoine and betaine, which therefore only function as compatible solutes when present in the environment (Frings et al., 1993; Farwick et al., 1995; Guillouet and Engasser, 1995; Wolf et al., 2003). Proline is the major de novo synthetized compatible solute in C. glutamicum (Skjerdal et al., 1996; Wolf et al., 2003). De novo biosynthesis of proline is induced under osmostress-conditions (Rönsch et al., 2003) unless nitrogen is scarce, a condition when trehalose is synthesized instead of proline (Wolf et al., 2003). Externally added proline can be taken up into the C. glutamicum cell by the import systems EctP, ProP, and PutP (Peter et al., 1998). The import of proline by the carriers EctP and ProP is osmoregulated (Peter et al., 1998), while the import of proline by PutP is not (Peter et al., 1997).

The cyclic amino acid L-pipecolic (L-PA), also known as homoproline, is a non-proteogenic amino acid and an intermediate of the catabolism of D,L-lysine (Neshich et al., 2013). L-PA is similar in chemical structure to L-proline since they only differ in ring size by one carbon (Pérez-García et al., 2016). L-PA plays many roles in microorganisms, plants, and animals; including the interactions between organisms and as precursor of natural bioactive molecules (Vranova et al., 2013). Notably, L-PA was reported as compatible solute for the microorganisms Silicibacter pomeroyi, Sinorhizobium meliloti, and Escherichia coli (Gouesbet et al., 1994; Gouffi et al., 2000; Neshich et al., 2013). E. coli does not degrade lysine to L-PA, but to cadaverine by the lysine decarboxylases LdcC or CadA (Mimitsuka et al., 2007; Kind et al., 2010). However, externally added L-PA protected E. coli cells under high osmolarity conditions (Gouesbet et al., 1994). C. glutamicum lacks lysine catabolic pathways, although the production of L-lysine-derived compounds has been established in C. glutamicum by metabolic engineering (Kind et al., 2010; Pérez-García et al., 2016; Jorge et al., 2017). A lysine producing C. glutamicum strain was engineered to overproduce L-PA by heterologous expression of the lysine dehydrogenase gene $(l y s D H)$ from $S$. pomeroyi and overexpression of the native pyrroline-5-carboxylate reductase gene (proC) from C. glutamicum (Pérez-García et al., 2016). However, the physiological role of L-PA for C. glutamicum has not yet been described. Here, we characterized the effect of L-PA on C. glutamicum (either added to the culture medium or synthesized de novo) under different conditions of osmotic pressure by physiological and RNAseq experiments. We provide evidence that YggB may be involved in export of L-PA and ProP in its import into the C. glutamicum cell.

\section{MATERIALS AND METHODS}

\section{Strain, Plasmids, and Culture Conditions}

The strains and plasmids used in this work are listed in Table 1. E. coli strains were routinely cultivated in LB medium (10 g tryptone, $5 \mathrm{~g}$ yeast extract and $10 \mathrm{~g} \mathrm{NaCl}$ per liter) or on LB agar plates at $37^{\circ} \mathrm{C}$. C. glutamicum strains were routinely precultivated in brain heart infusion $\left(\mathrm{BHI}, \mathrm{ROTH}^{\circledR}\right)$ plates or liquid medium overnight at $30^{\circ} \mathrm{C}$. For C. glutamicum main cultures in flask, CGXII medium (Eggeling and Bott, 2005) was inoculated to an initial $\mathrm{OD}_{600}$ of 1 using $4 \%$ $(\mathrm{w} / \mathrm{v})$ glucose as sole-carbon source. For C. glutamicum main cultures in BioLector (m2p-labs, Baesweiler, Germany), growth experiments were performed in Flowerplates at 1,000 rpm, $95 \%$ humidity, $30^{\circ} \mathrm{C}$ and backscatter gain 15 , inoculated to an initial $\mathrm{OD}_{600}$ of 1 and using $4 \%(\mathrm{w} / \mathrm{v})$ glucose as sole-carbon source. When necessary, the growth medium was supplemented with kanamycin $\left(25 \mu \mathrm{g} \mathrm{mL}^{-1}\right)$, spectinomycin $\left(100 \mu \mathrm{g} \mathrm{mL}^{-1}\right)$ and isopropyl $\beta$-D-1-thiogalactopyranoside (IPTG) (1 mM). For growth in hyperosmolar conditions 100,200 , or $400 \mathrm{mM}$ of $\mathrm{NaCl}$ were added to the medium.

\section{Molecular Biology Methods}

As host for gene cloning E. coli DH5 $\alpha$ was used (Hanahan, 1983). E. coli was transformed by heat shock following the method described elsewhere (Hanahan, 1983), while C. glutamicum was transformed by electroporation following the method described elsewhere (Eggeling and Bott, 2005). The pair of primers $\mathrm{YgFw} / \mathrm{YgRv}$ (Table 2) were used to amplified $y g g B$ from genomic DNA of C. glutamicum ATCC 13032. The pair of primers $\mathrm{PrFw} / \mathrm{PrRv}$ (Table 2) were used to amplified proP from genomic DNA of C. glutamicum ATCC 13032. The amplified genes were cloned by Gibson assembly (Gibson, 2011) into the vector pEKEx3 (Stansen et al., 2005) digested with BamHI, yielding the vectors pEKEx3-yggB and pEKEx3-proP. Positive clones were verified by colony PCR using the pair of primers X1Fw/X1Rv (Table 2). The up- and downstream regions of proP gene were amplified by PCR from genomic DNA of C. glutamicum ATCC 13032 using the pair of primers PrDA/PrDB and PrDC/PrDD. The up and down amplified fragments were fused by cross-over PCR with primer pair PrDA/PrDD and cloned by ligation (Eggeling and Bott, 2005) into the vector pK19mobsacB (Schäfer et al., 1994) restricted with BamHI. Positive clones were verified by colony PCR using the pair of primers 196F/197R (Table 2). The resulting vector pK19mobsacB- $g d h$ was transferred to E. coli S17-1. In-frame deletion of the $y g g B$ and proP genes from C. glutamicum was performed via a two-step homologous recombination method (Eggeling and Bott, 2005). The pK19mobsacB vectors were transferred to the GSL strain via conjugation using E. coli S17-1 (Simon et al., 1983). The deletions of $y g g B$ and proP were verified by colony PCR using the pair of primers DE31/DE32 and PrDE/PrDF, respectively.

\section{Internal Amino Acids Extraction}

For the quantification of intracellular L-PA $2 \mathrm{~mL}$ of liquid medium were collected. One milliliter was centrifuged at $14,000 \mathrm{rpm}$ and $4^{\circ} \mathrm{C}$ for $10-15 \mathrm{~min}$. The resulting pellets were resuspended and treated with $5 \% \mathrm{HClO}_{4}$ in an ice bath for $30 \mathrm{~min}$. Then, the supernatant was neutralized with $\mathrm{K}_{2} \mathrm{CO}_{3}$ solution and centrifuged again at $14,000 \mathrm{rpm}$ and $4^{\circ} \mathrm{C}$ for $10-15 \mathrm{~min}$. Afterward, the supernatants were directly used for L-PA quantification or stored at $-20^{\circ} \mathrm{C}$ 
TABLE 1 | Strains and plasmids used in this work.

\begin{tabular}{|c|c|c|}
\hline Strains and plasmids & Description & Source \\
\hline \multicolumn{3}{|l|}{ Strains } \\
\hline GSL & $\begin{array}{l}\text { C. glutamicum ATCC13032 with the following modifications: } \Delta p c k, \Delta s u g R, \Delta / d h A, p y c^{P 458 S} \text {, } \\
h^{V} m^{V 9 A} \text {, two copies of } / y s C^{T 311 /} \text {, two copies of asd, two copies of } d a p A \text {, two copies of dapB, two } \\
\text { copies of } d d h \text {, two copies of lysA, two copies of lysE, in-frame deletion of prophages CGP1 } \\
\text { (cg1507-cg1524), CGP2 (cg1746-cg1752), and CGP3 (cg1890-cg2071) }\end{array}$ & Pérez-García et al., 2016 \\
\hline GSL $\Delta y g g B$ & In-frame deletion of yggB (cg1434) in GSL & This work \\
\hline GSL $\Delta$ proP & In-frame deletion of proP (cg3395) in GSL & This work \\
\hline JJ001 & $\begin{array}{l}\text { C. glutamicum ATCC13032 with the following modifications: } \triangle \text { argF, } \Delta a r g R \text { (auxotrophic for } \\
\text { L-arginine); carrying the vector pWWEx1 }\end{array}$ & Jensen and Wendisch, 2013 \\
\hline JJ004 & JJ001 strain carrying the vector pWWEx1-ocdPp(TAA) & Jensen and Wendisch, 2013 \\
\hline E. coli $\mathrm{DH} 5 \alpha$ & 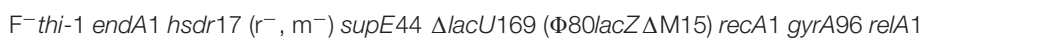 & Hanahan, 1983 \\
\hline E. coli S17-1 & recA, thi, pro, hsd R-M+ (RP4: 2-Tc:Mu-:Km, integrated into the chromosome) & Simon et al., 1983 \\
\hline \multicolumn{3}{|l|}{ Plasmids } \\
\hline pWWEx1 & KmR , C. glutamicum/E. coli shuttle vector (Ptac, lacl, pHM1519 oriV $\mathrm{Cg}$ ) & Peters-Wendisch et al., 2001 \\
\hline pEKEx3 & Spec $^{R}$, C. glutamicum/E. coli shuttle vector (Ptac, lacl, pBL1 ori $\left.V_{\mathrm{Cg}}\right)$ & Stansen et al., 2005 \\
\hline pWWEx1-lysDH-proC & $\begin{array}{l}\mathrm{Km}^{\mathrm{R}}, \mathrm{pWWEx} 1 \text { overexpressing lysDH from S. pomeroyi DSS-3 and proC from C. glutamicum ATCC } \\
13032\end{array}$ & Pérez-García et al., 2016 \\
\hline pEKEx3-yggB & Spe $^{R}$, pEKEx3 overexpressing yggB from C. glutamicum ATCC 13032 & This work \\
\hline pEKEx3-proP & Spe ${ }^{R}$, pEKEx3 overexpressing proP from C. glutamicum ATCC 13032 & This work \\
\hline pK19mobsacB & $\begin{array}{l}\mathrm{Km}^{\mathrm{R}} \text {; E. coli/C. glutamicum shuttle vector for construction of insertion and deletion mutants in } \\
\text { C. glutamicum (pK18 oriVEc sacB lacZ } \alpha \text { ) }\end{array}$ & Schaffer et al., 2001 \\
\hline pK19mobsacB- $\Delta y g g B$ & pK19mobsacB with a yggB (cg1434) deletion construct & Lubitz and Wendisch, 2016 \\
\hline pK19mobsacB- $\Delta$ proP & pK19mobsacB with a proP (cg3395) deletion construct & This work \\
\hline
\end{tabular}

TABLE 2 | Oligonucleotide sequences used in this work for molecular cloning and in-frame deletion.

\begin{tabular}{|c|c|}
\hline Primer & Sequence $(5 \rightarrow 3)$ \\
\hline PrFw & $\begin{array}{l}\text { GCATGCCTGCAGGTCGACTCTAGAGGAAAGGAGGCCCT } \\
\text { TCAGGTGAGCCCGATTCGCTC }\end{array}$ \\
\hline PrRv & $\begin{array}{l}\text { AATTCGAGCTCGGTACCCGGGGATCTTATGCGTITGCTा } \\
\text { TCAG }\end{array}$ \\
\hline YgFw & $\begin{array}{l}\text { GCATGCCTGCAGGTCGACTCTAGAGGAAAGGAGGCCCTTCA } \\
\text { GATGATITAGGCGTACCC }\end{array}$ \\
\hline YgRv & $\begin{array}{l}\text { AATTCGAGCTCGGTACCCGGGGATCCTAAGGGGTGGACG } \\
\text { TCGG }\end{array}$ \\
\hline PrDA & $\begin{array}{l}\text { GCATGCCTGCAGGTCGACTCTAGAGTTCGGTGCCCTCCACG } \\
\text { GCAC }\end{array}$ \\
\hline PrDB & GGGTAGGTGATITGAATITGTGAGTAAAACCTCTCGTCATATC \\
\hline PrDC & ACAAATTCAAATCACCTACCCCCGTAAAGCCCGCTGCAAGG \\
\hline PrDD & $\begin{array}{l}\text { AATTCGAGCTCGGTACCCGGGGATCGTAACGATGCAGACCG } \\
\text { CCGG }\end{array}$ \\
\hline $\operatorname{PrDE}$ & CGGTGCCCTCCACGGCACC \\
\hline PrDF & AACGATGCAGACCGCCGGCG \\
\hline DE31 & CTITGGCGCTCCAAGTACT \\
\hline DE32 & TCCTCGAGCGATCGAACAAT \\
\hline $\mathrm{X} 1 \mathrm{Fw}$ & CATCATAACGGTTCTGGC \\
\hline $\mathrm{X} 1 \mathrm{Rv}$ & АTCTTCTCTCATCCGCCA \\
\hline $196 F$ & CGCCAGGGTाTCCCAGTCACGAC \\
\hline 197R & AGCGGATAACAATाTCACACAGGA \\
\hline
\end{tabular}

(Sun et al., 2016). It has to be noted that the water space of the pellet in such a centrifugation step will contain compounds presents in the extracellular volume and this will affect the determination of the intracellular concentration. On the other hand, intracellular compounds may leak out of the cell during washing steps and this will also affect the determination of the intracellular concentration. Since all samples were processed in the same way, the possible fluctuations/errors in the measurements should affect all samples similarly. Exact quantitation would require methods such as described by Klingenberg and Pfaff (1967) which combine centrifugation through silicone oil for fast separation of supernatant and pellet by centrifugation and inactivation of the pellet by perchloric acid. The second collected $\mathrm{mL}$ was used to determine the biomass according to the correlation CDW $\left[\mathrm{g} \mathrm{L}^{-1}\right]=0.35$ OD (Bolten et al., 2007).

\section{Determination of L-PA by High Pressure Liquid Chromatography}

The concentration of L-PA was quantified by using high-pressure liquid chromatography. The samples from the cell cultures were collected by centrifugation $(14,000 \mathrm{rpm}, 15 \mathrm{~min}$ and at room temperature), and further used for analysis. The samples were derivatized with fluorenylmethyl chloroformate (FMOC) as described (Schneider and Wendisch, 2010). Amino acid separation was performed on a system consisting of a pre-column (LiChrospher $100 \mathrm{RP} 18 \mathrm{EC}-5 \mu(40 \times 4 \mathrm{~mm})$, CS-Chromatographie Service GmbH, Langerwehe, Germany) and a main column (LiChrospher 100 RP18 EC-5 $\mu$ $(125 \times 4 \mathrm{~mm})$, CS Chromatographie Service $\mathrm{GmbH})$. The detection was carried out with a fluorescence detector with the excitation and emission wavelength of $230 \mathrm{~nm}$ and $310 \mathrm{~nm}$, respectively (FLD G1321A, 1200 series, Agilent Technologies). 


\section{RNAseq Analysis}

For extraction of C. glutamicum bacterial cell pellets grown under the experimental conditions were harvested at mid-exponential phase. Harvesting procedure was done according to Irla et al. (2015) and cell pellets were kept at $-80^{\circ} \mathrm{C}$ for further RNA isolation. Then, the pellets were thawed in ice and RNA was isolated individually for each sample using NucleoSpin RNA isolation kit (Macherey-Nagel, Düren, Germany). RNA samples with genomic DNA contamination were treated with the RNase-free DNase set (Qiagen, Hilden, Germany) (Brito et al., 2017). The concentration of isolated RNA was determined by

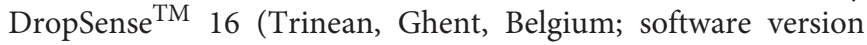
2.1.0.18). To verify the quality of RNA samples, we performed capillary gel electrophoresis (Agilent Bioanalyzer 2100 system using the Agilent RNA 6000 Pico kit; Agilent Technologies, Böblingen, Germany). The extracted RNA samples were pooled in equal parts and the pool of total RNA was subsequently used for the preparation of the cDNA libraries. The preparation and sequencing of the libraries were performed as described elsewhere (Mentz et al., 2013; Irla et al., 2015). Then, the reads were trimmed to a minimal length of 20 base pairs and in paired end mode with the Trimmotatic ver. 0.33 (Bolger et al., 2014). Trimmed reads were mapped to the reference genome of C. glutamicum ATCC13032 (Kalinowski et al., 2003) using the software Bowtie (Langmead et al., 2009). In order to perform differential gene expression analysis (DEseq) (Anders and Huber, 2010), we used the software for visualization of mapped sequences ReadXplorer (Hilker et al., 2014).

\section{Real-Time Quantitative Reverse Transcription-PCR}

The real-time quantitative reverse transcription-PCR (qRTPCR) was performed in order to validate the data obtained by DEseq analysis by using the CFX Connect ${ }^{\mathrm{TM}}$ Real-Time PCR Detection System (Bio-Rad Laboratories, Irvine, CA, United States). Same RNA samples utilized in the RNAseq analysis were utilized as templates for qRT-PCR. All samples RNA concentration was adjusted to $50 \mathrm{ng} \mu \mathrm{L}^{-1}$. Afterward, $1 \mu \mathrm{L}$ for each sample was pipetted into a reaction mix of the SensiFAST ${ }^{\mathrm{TM}} \mathrm{SYBR}^{\circledR}$ No-ROX Kit (Bioline, Luckenwalde, Germany), following manufacturer's instructions. Differentially expressed genes in DEseq analysis were selected as targets for qRT-PCR amplifications (primers listed in Table 3). The meltingcurve data-based quantification cycle $(\mathrm{Cq})$ values, from the LightCycler $^{\circledR}$ output files, were used for further calculation as it is described elsewhere (Crooks et al., 2004).

\section{RESULTS}

\section{C. glutamicum Can Use L-PA for Osmoprotection}

Structurally, L-PA is related to L-proline. To check whether L-PA functions as osmoprotectant in C. glutamicum the L-PA producer GSL(pVWEx1-lysDH-proC) (Pérez-García et al., 2016) was grown in glucose-minimal medium supplemented with $0,100,200$, and $400 \mathrm{mM}$ of $\mathrm{NaCl}$ using a BioLector system. Production of L -PA was induced by adding IPTG. When not induced for L-PA production, strains GSL(pVWEx1) and GSL(pVWEx1-lysDH-proC) showed decreasing growth rates (Figure 1A) and maximal biomass formation (Figure 1B) with increasing $\mathrm{NaCl}$ concentration. However, when L-PA production was induced, C. glutamicum GSL(pVWEx1-lysDH-proC) grew faster (Figure 1A) and to higher biomass concentrations (Figure 1B) in the presence of $\mathrm{NaCl}$ than the parent strain GSL(pVWEx1) (Figure 1). This indicated that biosynthesis of L-PA helps C. glutamicum to withstand hyperosmolar conditions.

To test if also exogenously added L-PA is beneficial for C. glutamicum when grown under hyperosmolar conditions, $40 \mathrm{mM}$ of either L-PA or L-proline were added to the glucose-minimal medium and growth of C. glutamicum GSL(pVWEx1) was monitored (Figures 1C,D). The exogenous addition of L-PA or L-proline improved growth of strain GSL(pVWEx1) in the presence of all $\mathrm{NaCl}$ concentrations tested (Figures 1C,D). Thus, under the chosen conditions L-PA functions as well as the known osmoprotectant of C. glutamicum, $\mathrm{L}$-proline, in promoting growth under hyperosmolar conditions.

TABLE 3 | Oligonucleotide sequences $(5 \rightarrow 3)$ used for amplification of gene fragments in qRT-PCR.

\begin{tabular}{|c|c|c|c|}
\hline Gene identity & Forward & Reverse & $\begin{array}{l}\text { Gene product } \\
\text { length (bp) }\end{array}$ \\
\hline betP & GCGGGCTTGCTTGAGAATCC & TGAAGGCCCAGCCGAGATTG & 232 \\
\hline $\operatorname{cg} 1665$ & GCTGCCAАCTCTGCAАCCTC & ССАTTCGGGCCTTCTTCCAC & 245 \\
\hline cg2677 & GGCTCTGCCTCCАTTCTITG & GGTTGTGCCTTGACCTCTTC & 210 \\
\hline cg2851 & CAACGTGAACACGGTGTATC & CACATCGTCGAATCCGTTTG & 210 \\
\hline gntV & TCCGTCGGTAAAGCCCTAGC & CGGTTCCTGGGCATTTGGTG & 238 \\
\hline proc & CGCGGCCAACATGAATCCAC & GGCCATGCTGACCACAACAC & 232 \\
\hline proP & TCGACTGGTGGTGAATATGC & GAATACGCCAACCGAAATCC & 202 \\
\hline pstC & AATGCGAACTCCTCTCAGAC & AATCCGCCAATACCTTCAGC & 206 \\
\hline psts & TCCGCAATGGACTACTTTGG & AACTGGGCCGATAACGAATG & 222 \\
\hline
\end{tabular}


A

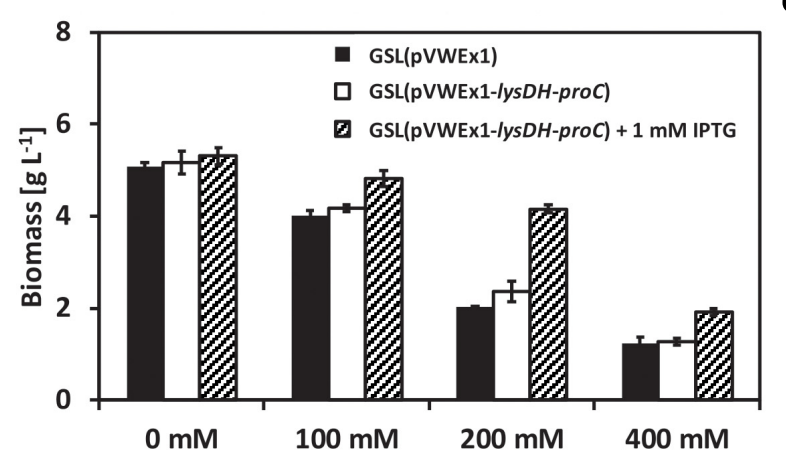

B

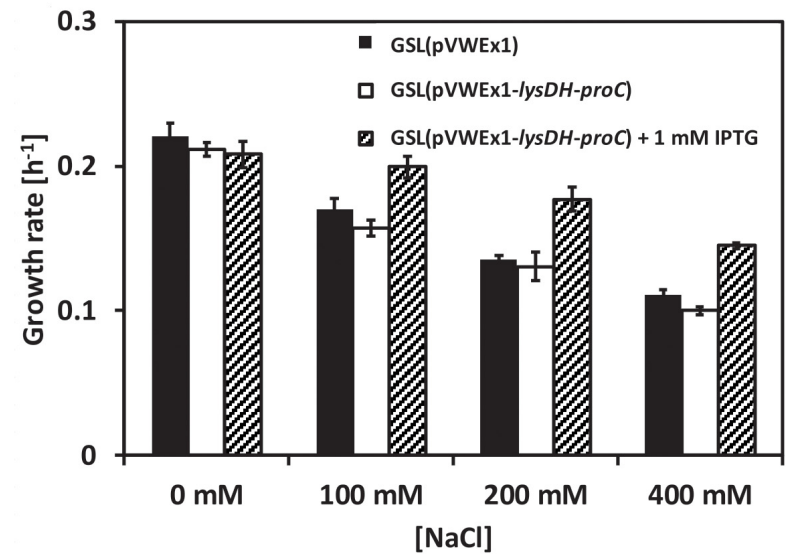

C

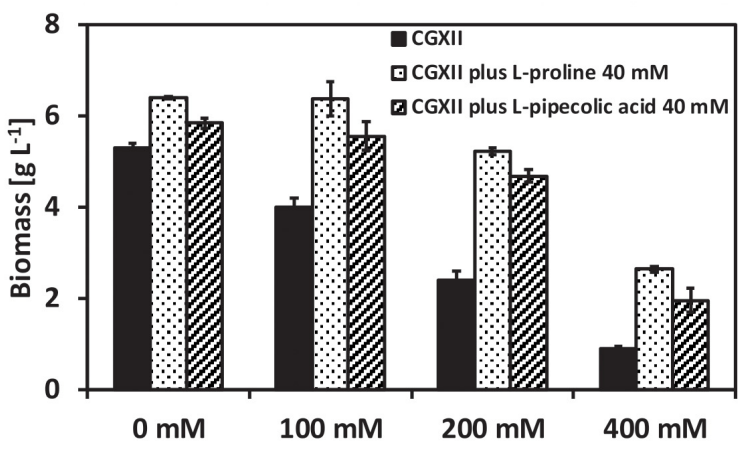

D

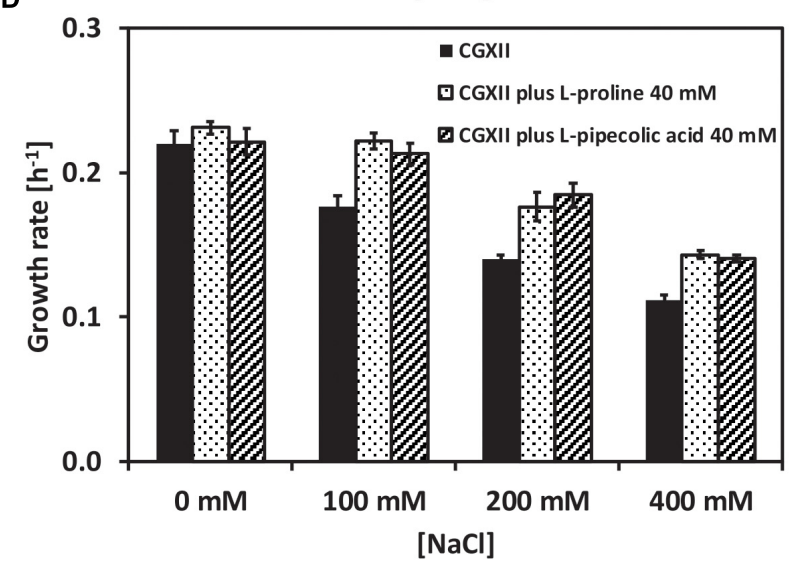

FIGURE 1 | Growth of the C. glutamicum strains GSL(pWWEx1) and GSL(pWWEx1-lysDH-proC) under different osmotic conditions. (A) Biomass formation in g L-1 of GSL(pVWEx1) and GSL(pVWEx1-lysDH-proC) strains in glucose minimal medium supplemented with 0, 100, 200, or 400 mM of NaCl. (B) Growth rates values in $\mathrm{h}^{-1}$ of GSL(pVWEx1) and GSL(pVWEx1-lysDH-proC) strains in glucose minimal medium supplemented with 0, 100, 200, or 400 mM of NaCl. (C) Biomass formation in $\mathrm{g} \mathrm{L}^{-1}$ of GSL(pWWEx1) strain in glucose minimal medium supplemented with 0,100 , 200, or $400 \mathrm{mM}$ of $\mathrm{NaCl}$ with $40 \mathrm{mM}$ of $\mathrm{L}-\mathrm{proline}$ or $40 \mathrm{mM}$ of L-PA or nothing. (D) Growth rates values in $\mathrm{h}^{-1}$ of GSL(pWWEx1) strain in glucose minimal medium supplemented with 0, 100,200 , or $400 \mathrm{mM}$ of $\mathrm{NaCl}$ with $40 \mathrm{mM}$ of L-proline or $40 \mathrm{mM}$ of L-PA or nothing. Values represent means and standard deviations.

While several transport proteins for the compatible solute L-proline are known, transport of L-PA has not yet been studied.

\section{The Mechanosensitive Channel YggB May Play a Role as Escape Valve for L-PA}

Osmo compatible solutes accumulate intracellularly under hyperosmolar conditions and are released from the cell upon osmotic downshift. Since YggB has been shown to be a key player in osmoregulation in C. glutamicum (Börngen et al., 2010), $y g g B$ deletion mutants were also analyzed. Here, the accumulation and release of L-PA by C. glutamicum cells were analyzed (Figure 2). C. glutamicum cells were cultivated in $50 \mathrm{~mL}$ glucose-minimal medium without (blue columns) or with (red columns) $200 \mathrm{mM} \mathrm{NaCl}$. When glucose was depleted $1 \mathrm{~mL}$ supernatant and $2 \mathrm{~mL}$ pellet were collected to measure the extracellular (dashed columns) and intracellular (filled columns) concentrations of L-PA (Figure 2, left panels). The rest of the pellet of cells that grew in CGXII (blue lines) or CGXII + $200 \mathrm{mM} \mathrm{NaCl}$ (red lines) was transferred to $35 \mathrm{~mL}$ milliQ-water $0.9 \% \mathrm{NaCl}$ to force an osmotic downshift while keeping the cells intact. The extracellular (dashed lines) and intracellular (solid lines) concentrations of L-PA were monitored over time (Figure 2, right panels). The experiment was performed with the L-PA producing strain GSL(pVWEx1-lysDH-proC) (Figure 2A); a $y g g B$ deletion mutant of this strain lacking the MSC YggB, GSL $\Delta y g g B(p V W E x 1-l y s D H-p r o C$ ) (Figure 2B); and a derived strain expressing $y g g B$ from a plasmid for complementation of the $y g g B$ deletion, GSL $\Delta y g g B(\mathrm{pVWEx}$-lysDH-proC)(pEKEx3$y g g B$ ) (Figure 2C). After growth in CGXII minimal medium with $200 \mathrm{mM} \mathrm{NaCl}$, the intracellular L-PA concentrations were higher than after growth in CGXII minimal medium without added $\mathrm{NaCl}$ (Figure 2A), left). Upon osmotic downshift, L-PA was released from cells grown without $\mathrm{NaCl}$ and accumulated in the medium with a rate of $0.97 \pm 0.04 \mathrm{mM} \mathrm{h}^{-1}$. However, when cells grown with $200 \mathrm{mM} \mathrm{NaCl}$ were subjected to osmotic downshift, L-PA was released with a $75 \%$ higher rate and to an about 1.6 higher concentration (Figure 2A, right and Table 4).

When growing the strain GSL $\Delta y g g B(\mathrm{pVWEx} 1-l y s D H$ proC) on CGXII with or without $200 \mathrm{mM} \mathrm{NaCl}$ the internal accumulation of L-PA increased 80 and $40 \%$, respectively, as compared with the strain GSL(pVWEx1-lysDH-proC) 


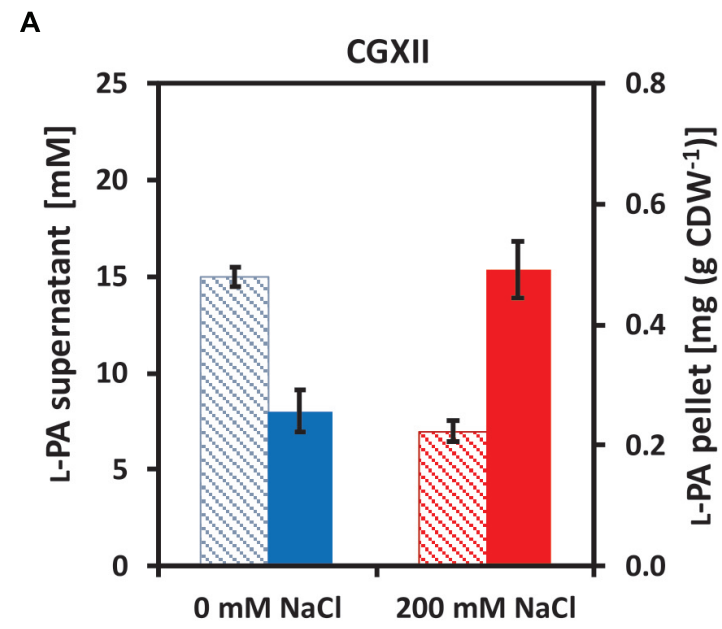

B

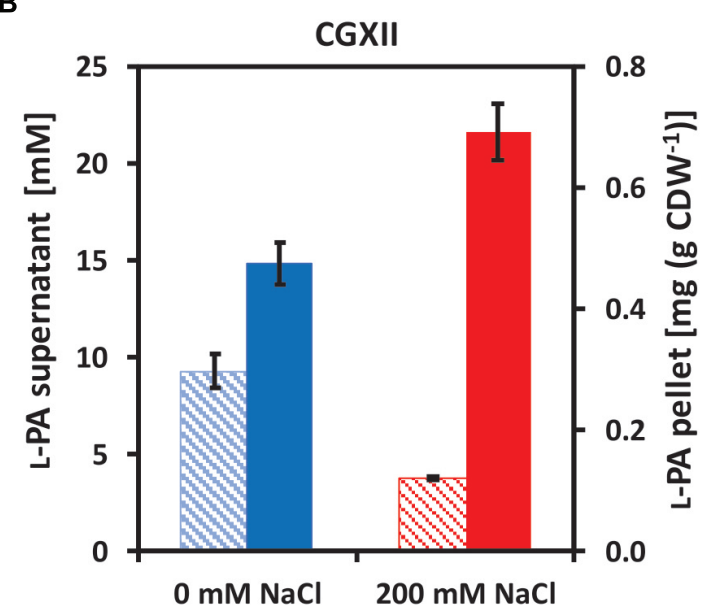

C

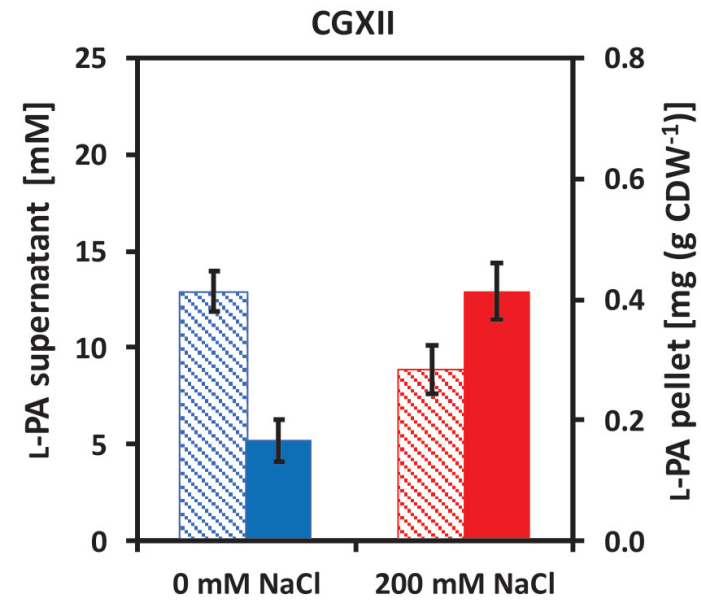

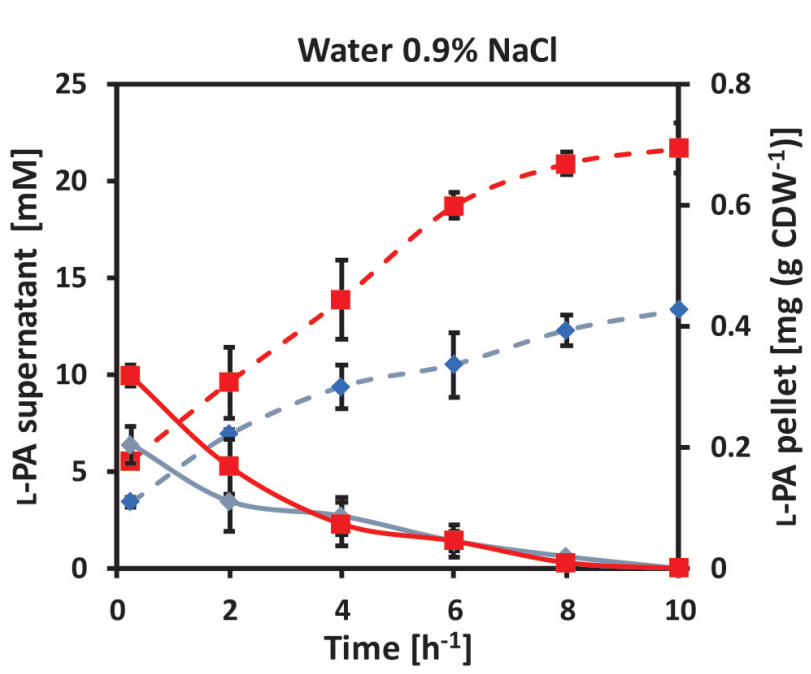

Water $0.9 \% \mathrm{NaCl}$
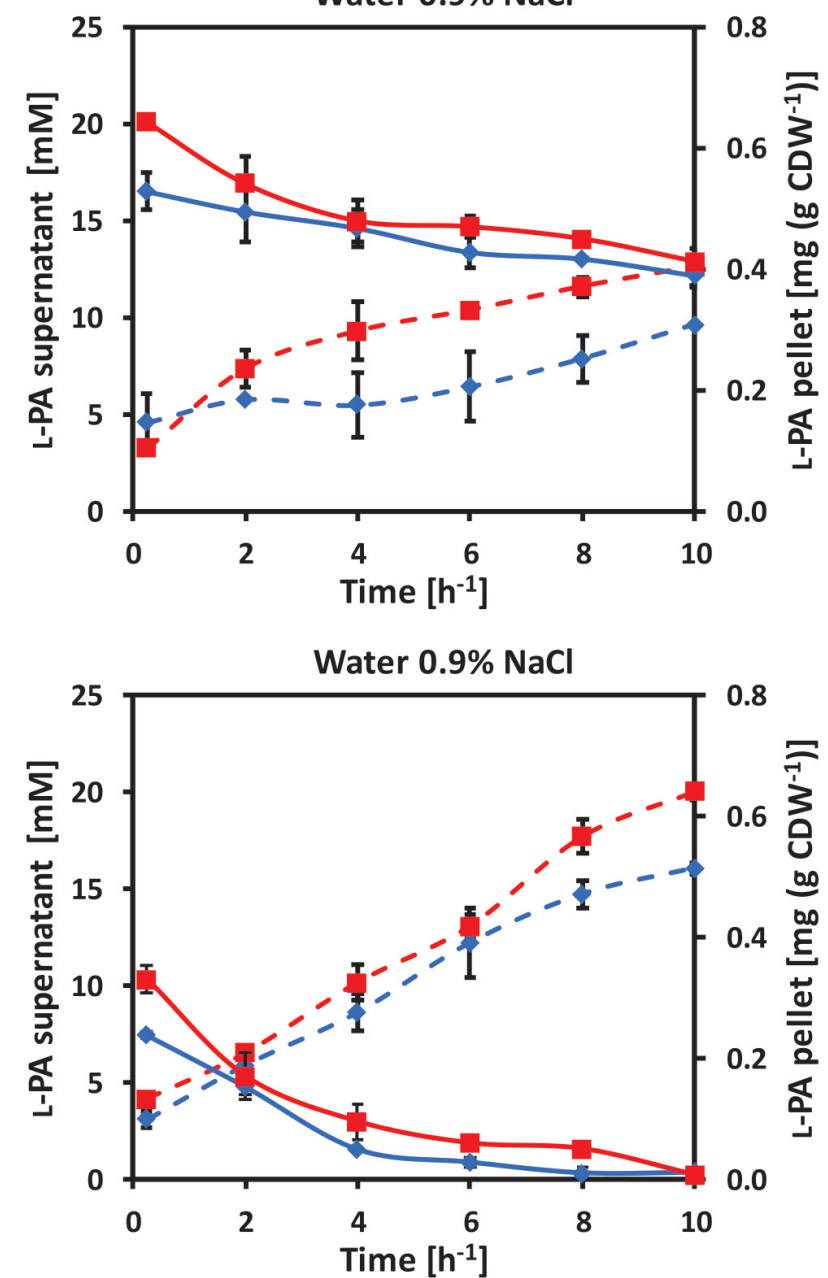

FIGURE 2 | Intracellular (filled columns, straight lines) and extracellular (dashed columns, dashed lines) L-PA concentration profiles of the strains (A) GSL(pWWEx1-lysDH-proC), (B) GSL $\Delta y g g B$ (pWWEx1-lysDH-proC) and (C) GSL $\Delta y g g B$ (pVWEx1-lysDH-proC)(pEKEx3-yggB) after growth in glucose-minimal medium (left panels) without added $\mathrm{NaCl}$ (blue) or with $200 \mathrm{mM} \mathrm{NaCl}$ (red) and after osmotic downshift to $0.9 \% \mathrm{NaCl}$ (right panels). Values represent means and standard deviations. 
TABLE 4 | Rates of decrease of intracellular L-PA concentrations and of L-PA accumulation in the cultivation medium upon osmotic downshock of different C. glutamicum strains after growth in glucose minimal medium with or without $200 \mathrm{mM} \mathrm{NaCl}$.

\begin{tabular}{|c|c|c|c|c|}
\hline \multirow[b]{2}{*}{ Strain } & \multicolumn{2}{|c|}{$\begin{array}{l}\text { Rates of decrease of intracellular L-PA } \\
\text { concentrations }\left(\mu \mathrm{g} \mathrm{g} \mathrm{CDW}^{-1} \mathrm{~h}^{-1}\right)\end{array}$} & \multicolumn{2}{|c|}{$\begin{array}{l}\text { Rates of L-PA accumulation } \\
\text { in the supernatant }\left(\mathrm{mM} \mathrm{h}^{-1}\right)\end{array}$} \\
\hline & $\begin{array}{l}\text { After growth with } \\
\qquad \mathrm{OMM} \mathrm{NaCl}\end{array}$ & $\begin{array}{l}\text { After growth with } \\
200 \mathrm{mM} \mathrm{NaCl}\end{array}$ & $\begin{array}{l}\text { After growth with } \\
\qquad \mathrm{mM} \mathrm{NaCl}\end{array}$ & $\begin{array}{l}\text { After growth with } \\
200 \mathrm{mM} \mathrm{NaCl}\end{array}$ \\
\hline GSL(pWWEx1-lysDH-proC) & $19.3 \pm 0.2$ & $30.2 \pm 0.4$ & $0.97 \pm 0.04$ & $1.73 \pm 0.02$ \\
\hline GSL $\boldsymbol{\Delta} \boldsymbol{y g} \boldsymbol{g} \boldsymbol{B}(\mathrm{pWWEx1-lysDH-proC)}$ & $14.0 \pm 0.2$ & $20.8 \pm 0.3$ & $0.47 \pm 0.13$ & $0.88 \pm 0.17$ \\
\hline 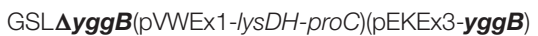 & $22.9 \pm 0.3$ & $28.9 \pm 0.4$ & $1.37 \pm 0.16$ & $1.68 \pm 0.14$ \\
\hline
\end{tabular}

Values represent means and standard deviations. Important strain features are depicted in bold.

(Figure 2B, left). On $0.9 \% \mathrm{NaCl}$, the L-PA external accumulation rates decreased to the half (Figure $\mathbf{2 B}$, right and Table 4). Therefore, the deletion of $y g g B$ slowed down L-PA export but was not enough to fully avoid it. The strain

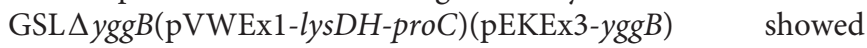
similar L-PA internal/external profiles in both CGXII and water as compared with the strain GSL(pVWEx1-lysDH-proC) (Figure 2C, right and Table 4).

\section{Comparative RNAseq Analysis of a L-PA Producing C. glutamicum Strain, a L-Proline Producing Strain and the Respective Control Strains}

Under the assumption that genes relevant for production of either L-PA or L-proline are differentially expressed when comparing L-PA producing C. glutamicum strain GSL(pVWEx1lysDH-proC) with its parent strain GSL(pVWEx1) and of L-proline producing C. glutamicum strain JJ004 with its parent strain JJ001, comparative RNAseq analysis was performed. C. glutamicum strains GSL(pVWEx1-lysDHproC), GSL(pVWEx1), JJ004 and JJ001 were grown in glucose minimal medium with $1 \mathrm{mM}$ IPTG after inoculation with an initial OD600 of 1 . Samples for RNA preparation were harvested after $8 \mathrm{~h}$ of inoculation at an OD600 of $7.6 \pm 0.4$ and $7.7 \pm 0.4$, respectively, for strains GSL(pVWEx1-lysDH-proC) and GSL(pVWEx1). Sample for strains JJ004 and JJ001 were harvested $6 \mathrm{~h}$ after inoculation at an OD600 of $7.6 \pm 0.1$ and $8.0 \pm 0.2$, respectively. RNA and library preparation, sequencing, read mapping and differential gene expression analysis using the statistical method DEseq (Naville et al., 2011) was performed as described in Section "Materials and Methods." Full data is available as Gene Expression Omnibus GSE122249 data set at http://www.ncbi.nlm.nih.gov/geo/. As compared to the respective control strains, 5 genes showed increased RNA levels and 17 genes decreased RNA levels in the L-PA producing strain, while 26 genes showed increased RNA levels and 33 genes decreased RNA levels in the L-proline producing strain (Table 5).

The results obtained in the RNAseq analysis were validated by the analysis of gene expression patterns by qRT-PCR. For each analysis eight genes were selected, four upregulated and four downregulated genes. As shown in Figure 3, the relative gene expression levels obtained in qRT-PCR confirmed the pattern of their differential gene expression (fold change value) obtained in the RNAseq analysis.

In the L-proline producing strain JJ004, pstSCAB encoding phosphate $\mathrm{ABC}$ uptake system, genes for divalent metal transporter proteins (ctpA, cg0569, cg3281, cg3282, and cg3402), for transcriptional regulators $(g l y R$, whiB3, and $w h c E$ ) and for enzymes of central carbon metabolism ( $p c k$, $l d h$ and mez) showed higher RNA levels than in the control strain JJ001 (Table 5). As compared to JJ001, RNA levels were lower in JJ004 for genes encoding iron-siderophore ABC uptake systems (cg0770, irp1, cg0924 and cg0926), the lysine/arginine permease gene lysE and genes for uptake of L-proline and other compatible solutes (betP, putP and proP) (Table 5). Thus, it appears that upon overproduction of L-proline, genes for its uptake from the culture medium are downregulated.

As expected, RNAseq analysis of the L-PA producing strain revealed increased expression of pyrroline-5-carboxylate reductase gene proC since it is expressed from plasmid pVWEx1lysDH-proC (Table 5). Other genes showing increased RNA levels upon L-PA production were the divalent metal transporter protein gene cg0569, the gluconokinase gene gnt $V$ and the catechol 1,2-dioxygenase gene catA (Table 5). Genes showing decreased RNA levels upon L-PA production were the putative site-specific recombinase gene xerC and the compatible solute transport gene proP (Table 5). Notably, the genes betP and putP coding for uptake systems of L-proline and other compatible solutes did not show increased RNA levels. Thus, ProP was chosen as potential candidate for import of L-PA into the C. glutamicum cell.

\section{Role of the Carrier ProP During Growth With L-PA as Osmo Compatible Solute}

Deduced from the RNAseq data, we speculated that the carrier ProP may play a role with regard to L-PA as osmo compatible solute of C. glutamicum. ProP is used by C. glutamicum as the main osmoregulated uptake system for L-proline (Peter et al., 1998). To test if the absence of ProP affects the use of C. glutamicum of L-PA under hyperosmolar conditions, strain GSL $\triangle$ proP was constructed. The strains GSL(pEKEx3) (Figure 4, black columns), GSL $\Delta$ proP(pEKEx3) (Figure 4, red columns) and GSL $\triangle$ proP(pEKEx3-proP) (Figure 4, green columns) were grown in glucose minimal medium supplemented with 0,100 , 200 , or $400 \mathrm{mM}$ of $\mathrm{NaCl}$ using a BioLector system. CGXII 
TABLE 5 | Comparative RNAseq analysis of L-proline producing strain JJ004, its isogenic non-producing control strain JJ001, L-PA producing C. glutamicum strain GSL(pVWEx1-lysDH-proC) and its isogenic non-producing control strain GSL(pVWEx1).

\begin{tabular}{|c|c|c|c|}
\hline \multirow[b]{2}{*}{ Locus or gene } & \multirow[b]{2}{*}{ Product } & \multicolumn{2}{|c|}{$\begin{array}{l}\log _{2} \text { fold change of RNA } \\
\text { level }(P \text {-value }<0.01)\end{array}$} \\
\hline & & $\begin{array}{c}\text { JJ004/ control } \\
\text { JJ001 }\end{array}$ & $\begin{array}{l}\text { GSL(pVWEx1-lysDH- } \\
\text { proC)/ control } \\
\text { GSL(pVWEx1) }\end{array}$ \\
\hline cg0018 & Conserved hypothetical membrane protein & 0.8 & -1.0 \\
\hline cg0107 & Putative secreted protein & 0.3 & -1.0 \\
\hline $\operatorname{cg} 0175$ & Putative secreted protein & -0.8 & -1.2 \\
\hline cg0282 & CsbD family protein involved in stress response & -0.8 & -0.6 \\
\hline $\operatorname{ctp} A$ & Putative $\mathrm{Cu}^{2+}$ transporting P-type ATPase & 1.1 & 0.2 \\
\hline proc & Pyrroline-5-carboxylate reductase & 0.0 & 4.7 \\
\hline glyR & Transcriptional activator of glyA, ArsR-family & 1.0 & -0.5 \\
\hline $\operatorname{cg} 0569$ & Putative $\mathrm{Cd}^{2+}$ transporting P-type ATPase & 1.0 & 1.7 \\
\hline whiB3 & Transcriptional regulator protein, WhiB-family & 2.6 & -0.5 \\
\hline prpC2 & 2-Methylcitrate synthase & 0.9 & 0.7 \\
\hline cg0770 & ABC-type putative iron-siderophore transporter, permease subunit & -1.9 & 0.3 \\
\hline irp1 & ABC-type putative iron-siderophore transporter, substrate-binding lipoprotein & -2.3 & -0.3 \\
\hline whcE & Transcriptional regulator, WhiB-family & 0.8 & -0.4 \\
\hline$p d x S$ & Pyridoxal 5'-phosphate (PLP) synthase subunit S & -0.8 & 0.0 \\
\hline$p d x T$ & Pyridoxal 5'-phosphate (PLP) synthase subunit T & -1.0 & 0.5 \\
\hline cg0924 & ABC-type putative iron-siderophore transporter, substrate-binding lipoprotein & -1.7 & -0.5 \\
\hline $\operatorname{cg0926}$ & ABC-type putative iron-siderophore transporter, permease subunit & -1.3 & -0.2 \\
\hline cg0935 & Conserved hypothetical protein & -0.4 & -1.3 \\
\hline rpf1 & RPF-protein precursor & 0.9 & -0.4 \\
\hline cg0952 & Putative integral membrane protein & -0.9 & -0.3 \\
\hline betP & $\mathrm{Na}^{+} /$glutamate symporter & -1.2 & -0.7 \\
\hline $\operatorname{cg} 1091$ & Hypothetical protein & -1.6 & -1.0 \\
\hline $\operatorname{cg} 1091$ & Hypothetical protein & -1.6 & -1.0 \\
\hline $\operatorname{cg} 1109$ & Hypothetical protein & -0.3 & -1.1 \\
\hline cg1279 & Putative secreted protein & 0.8 & 0.6 \\
\hline cg1291 & Putative membrane protein & 1.2 & -0.1 \\
\hline $\operatorname{cg} 1293$ & Putative secreted protein & -0.8 & -0.4 \\
\hline putP & $\mathrm{Na}^{+} /$proline symporter & -0.8 & -0.1 \\
\hline $\operatorname{cg} 1419$ & Putative secondary $\mathrm{Na}^{+} /$bile acid symporter, bile acid: $\mathrm{Na}^{+}$symporter (BASS) family & -1.7 & -0.2 \\
\hline lysE & L-Lysine efflux permease & -5.4 & -0.5 \\
\hline leuC & 3-Isopropylmalate dehydratase, large subunit & -0.8 & 0.0 \\
\hline ptsG & Phosphotransferase system (PTS), glucose-specific enzyme IIBCA component & -0.9 & 0.1 \\
\hline $\operatorname{cg} 1604$ & Secreted protein, putative channel protein & -0.9 & 0.1 \\
\hline $\operatorname{cg} 1665$ & Putative secreted protein & -1.7 & -0.9 \\
\hline $\operatorname{cg} 1746$ & Putative membrane protein & 0.8 & n.d. \\
\hline $\operatorname{cg} 1897$ & Putative secreted protein & -3.1 & n.d. \\
\hline $\operatorname{cg} 1930$ & Putative secreted hydrolase & -1.1 & n.d. \\
\hline cg2068 & Hypothetical protein & -1.0 & n.d. \\
\hline psp1 & Putative secreted protein & -1.6 & n.d. \\
\hline int2' & Putative phage Integrase ( $\mathrm{N}$-terminal fragment) & -1.6 & n.d. \\
\hline $\operatorname{cg} 2181$ & ABC-type putative dipeptide/oligopeptide transporter, substrate-binding lipoprotein & -0.8 & 0.1 \\
\hline xerC & Putative site-specific recombinase & -0.2 & -1.2 \\
\hline $\operatorname{cg} 2402$ & Secreted protein NLP/P60 family & 0.8 & -0.1 \\
\hline cg2425 & Putative permease & 0.7 & 0.3 \\
\hline cg2477 & Conserved hypothetical protein & 0.0 & -0.8 \\
\hline cg2564 & Conserved hypothetical protein & -1.7 & -0.5 \\
\hline catA & Catechol 1,2-dioxygenase & 0.3 & 0.7 \\
\hline cg2651 & Conserved hypothetical protein, pseudogene & -0.6 & -1.4 \\
\hline
\end{tabular}




\begin{tabular}{|c|c|c|c|}
\hline \multirow[b]{2}{*}{ Locus or gene } & \multirow[b]{2}{*}{ Product } & \multicolumn{2}{|c|}{$\begin{array}{c}\log _{2} \text { fold change of RNA } \\
\text { level }(P \text {-value }<0.01)\end{array}$} \\
\hline & & $\begin{array}{c}\text { JJ004/ control } \\
\text { JJ001 }\end{array}$ & $\begin{array}{c}\text { GSL(pVWEx1-lysDH } \\
\text { proC)/ control } \\
\text { GSL(pVWEx1) }\end{array}$ \\
\hline $\operatorname{cg} 2677$ & ABC-type putative dipeptide/oligopeptide transporter, permease subunit & 0.0 & 0.9 \\
\hline gntV & Gluconokinase & -0.5 & 1.8 \\
\hline rpmJ & $50 S$ ribosomal protein L36 & -0.3 & -1.0 \\
\hline pstB & ABC-type phosphate transporter, ATPase subunit & 1.3 & 0.1 \\
\hline pstA & ABC-type phosphate transporter, permease subunit & 1.2 & 0.5 \\
\hline pstC & ABC-type phosphate transporter, permease subunit & 1.5 & 0.3 \\
\hline pstS & ABC-type phosphate transporter, substrate-binding lipoprotein & 1.3 & 0.1 \\
\hline $\operatorname{cg} 2851$ & Branched-chain amino acid aminotransferase, AT class III/4-amino-4-deoxychorismate lyase & 0.0 & -1.6 \\
\hline $\operatorname{cg} 2875$ & Hypothetical protein & 0.8 & -0.3 \\
\hline $\operatorname{cg} 2908$ & Putative membrane protein & -1.0 & 0.1 \\
\hline pck & Phosphoenolpyruvate carboxykinase (GTP) & 0.8 & 0.0 \\
\hline gntP & Gluconate: $\mathrm{H}^{+}$symporter & -1.0 & 0.1 \\
\hline $\operatorname{cg} 3218$ & Pyruvate kinase-like protein & 1.2 & 0.4 \\
\hline ldh & L-Lactate dehydrogenase, NAD-dependent & 0.9 & 0.0 \\
\hline $\operatorname{cg} 3254$ & Putative membrane protein & -0.8 & -0.9 \\
\hline $\operatorname{cg} 3271$ & SAM-dependent methyltransferase & 0.3 & -1.1 \\
\hline $\operatorname{cg} 3281$ & Putative $\mathrm{Cu}^{2+}$ transporting P-type ATPase & 1.2 & -0.4 \\
\hline $\operatorname{cg} 3282$ & Putative $\mathrm{Cu}^{2+}$ transporting P-type ATPase & 1.4 & 0.0 \\
\hline $\operatorname{cg} 3326$ & Hypothetical protein & 1.1 & 0.8 \\
\hline mez & Malic enzyme & 0.9 & 0.3 \\
\hline proP & Proline/betaine permease & -1.2 & -1.2 \\
\hline $\operatorname{cg} 3402$ & Putative $\mathrm{Hg}^{2+}$ permease, MerTP-family & 1.2 & 0.0 \\
\hline cg3404 & ABC-type putative iron(III) dicitrate transporter, substrate-binding lipoprotein & -2.1 & -0.4 \\
\hline $\operatorname{cg} 4014$ & Conserved hypothetical protein, possibly involved in stress response & 0.3 & -1.0 \\
\hline $\operatorname{cg} 4019$ & & 0.8 & 0.1 \\
\hline $\operatorname{cg} 4021$ & & -0.6 & -1.1 \\
\hline
\end{tabular}

Names of genes used for subsequent qRT-PCR analysis are given in bold. n.d., not detected.

contains $200 \mathrm{mM}$ MOPS buffer, thus, has a relatively high osmolarity: about 1,1 osmol/kg without added $\mathrm{NaCl}$ as compared to about 1,3 osmol/kg CGXII medium with $400 \mathrm{mM} \mathrm{NaCl}$ (Börngen et al., 2010). In addition, the effect of externally added L-proline or L-PA was tested. Data for final biomass formation and growth rate was collected for all conditions (Figure 4). It was observed that the strains carrying the deletion of proP suffered more from the hyperosmotic conditions as compared to the control C. glutamicum strain GSL(pEKEx3) or the complementation strain GSL $\triangle$ proP(pEKEx3-proP) (Figure 4). When $40 \mathrm{mM}$ of L-proline was supplemented as osmo compatible solute to the minimal medium the growth rates and final biomass concentrations were reduced to a lesser extent than when $40 \mathrm{mM}$ L-PA was added (Figure 4). Thus, ProP plays an important role when L-proline and L-PA are used as osmo compatible solutes in $C$. glutamicum. These findings are commensurate with the view that ProP does not only import L-proline into the C. glutamicum cell, but also L-PA. However, future in depth biochemical analysis of L-PA uptake are needed to determine the respective kinetic parameters of L-PA uptake.

\section{DISCUSSION}

In this study, L-PA was shown to be an osmo compatible solute for C. glutamicum. L-PA cannot be synthesized by C. glutamicum wild type, but can be imported from the environment. The synthesis and/or accumulation of compatible solutes is a widespread microbial strategy against osmolarity fluctuations (da Costa et al., 1998; Kempf and Bremer, 1998; Wood et al., 2001; Czech et al., 2018). High cytoplasmic concentrations of compatible solutes also stabilize protein folding and ribosomes and protect the DNA, increasing the resistance to other types of stress such as high and low temperatures and radiation (Li and Gänzle, 2016; Sajjad et al., 2018; Tribelli and López, 2018). The osmoprotection mechanisms for the microbial cell factories E. coli, Bacillus subtilis and C. glutamicum are described (Kempf and Bremer, 1998; Wood et al., 2001; Morbach and Krämer, 2003; Hoffmann and Bremer, 2017). These and other non-halophilic bacteria accumulate $\mathrm{K}$ ions, $\mathrm{Na}$ ions or glutamate after an osmotic upshock as first response before these ions are exchanged against compatible solutes either by synthesis or uptake (Wood, 1999). C. glutamicum either synthesizes glutamine, proline or 

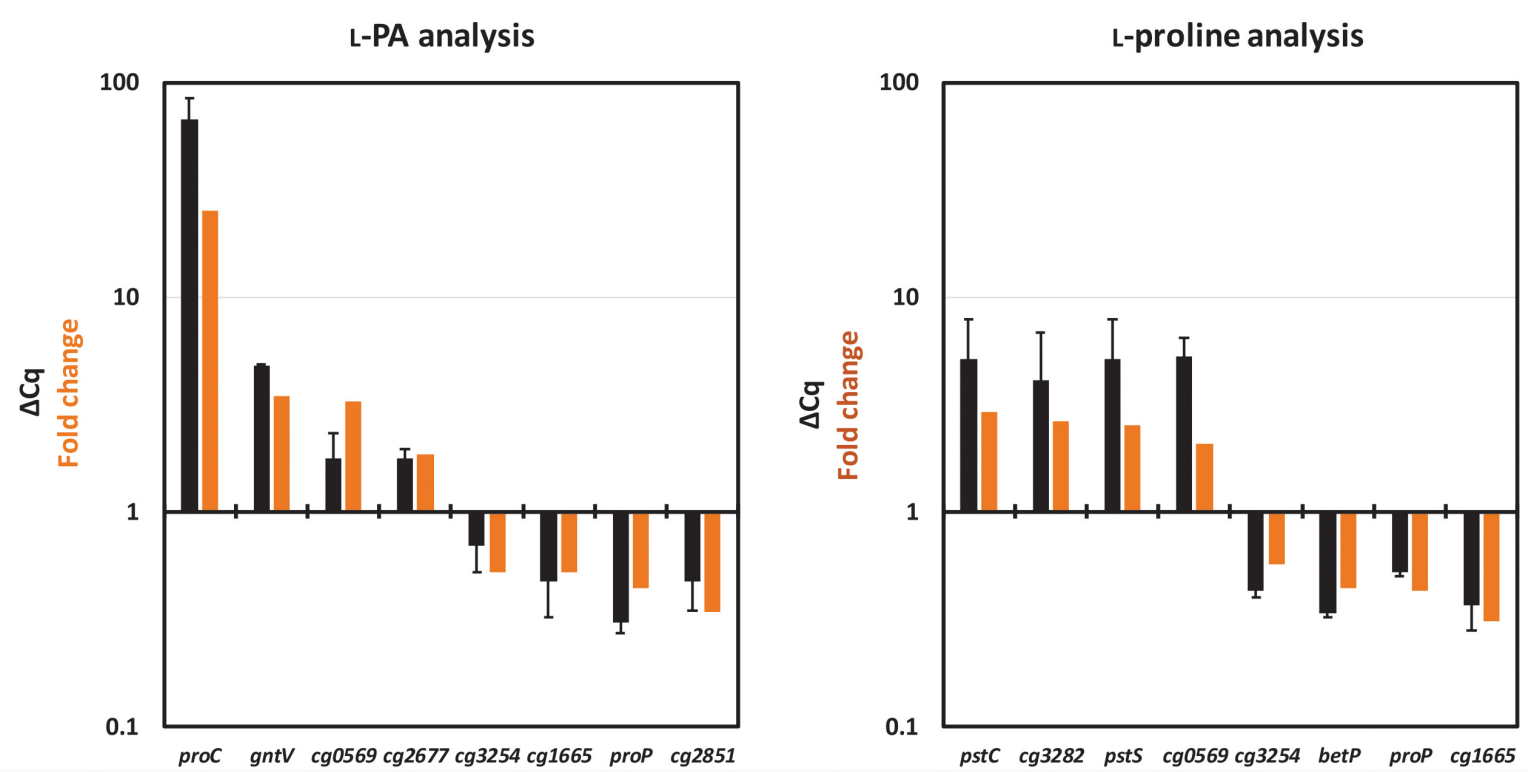

FIGURE 3 | Comparison of relative gene expression values obtained by qRT-PCR analysis (black bars) with those obtained by RNAseq analysis (orange bars). RNAseq data from Table 5 and qRT-PCR data $(\Delta \mathrm{Cq})$ collected for the L-PA analysis (left) and for the L-proline analysis (right) are listed. The values from the QRT-PCR are given as means and standard deviations.
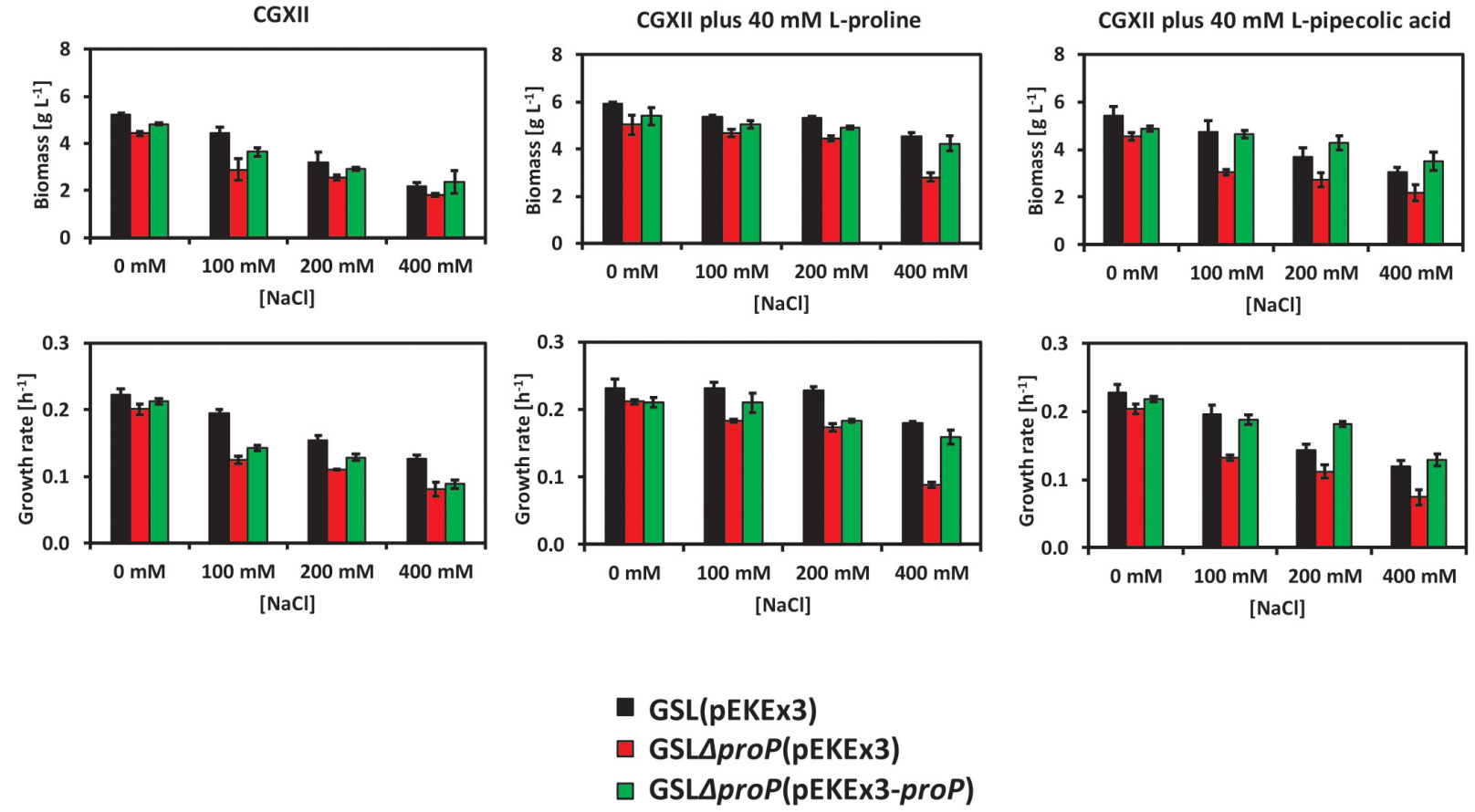

FIGURE 4 | Growth behavior of the C. glutamicum strains GSL(pEKEx3) (black bars), GSL $\Delta$ proP(pEKEx3) (red bars) and GSL $\Delta$ proP(pEKEx3-proP) (green bars) under different osmotic conditions. Biomass formation in $\mathrm{g} \mathrm{L}^{-1}$ (top-left) and growth rate in $\mathrm{h}^{-1}$ (down-left) when growing the strains in glucose minimal medium supplemented with $0,100,200$, or $400 \mathrm{mM}$ of NaCl. Biomass formation in $\mathrm{g} \mathrm{L}^{-1}$ (top-middle) and growth rate in $\mathrm{h}^{-1}$ (down-middle) when growing the strains in glucose minimal medium supplemented with $0,100,200$, or $400 \mathrm{mM}$ of $\mathrm{NaCl}$ an in presence of $40 \mathrm{mM}$ of L-proline. Biomass formation in $\mathrm{g} \mathrm{L}^{-1}$ (top-right) and growth rate in $\mathrm{h}^{-1}$ (down-right) when growing the strains in glucose minimal medium supplemented with $0,100,200$, or $400 \mathrm{mM}$ of $\mathrm{NaCl}$ an in presence of $40 \mathrm{mM}$ of L-PA. Values represent means and standard deviations. 
trehalose after an osmotic upshift or imports glycine betaine, proline or ectoine (Frings et al., 1993; Guillouet and Engasser, 1995; Skjerdal et al., 1996). In C. glutamicum, biosynthesis of proline involves one set of genes ( $p r o A$ for g-glutamyl phosphate reductase, $\operatorname{pro} B$ for g-glutamyl kinase and pro $C$ for pyrroline 5-carboxylate reductase), while $B$. subtilis possesses one set of proline biosynthesis genes for anabolic purposes and a second osmostress-induced set (Bremer, 2000). Similarly, biosynthesis and internal content of L-PA is regulated by external osmolality in Brevibacterium ammoniagenes (Gouesbet et al., 1992). It has been described that C. glutamicum prefers uptake of compatible solutes to their synthesis because uptake of compatible solutes is faster and energetically more favorable than their synthesis (Morbach and Krämer, 2003). In C. glutamicum, glycine betaine is the most effective osmoprotectant among those that can be imported from the environment, followed by ectoine and proline (Farwick et al., 1995). Here, we have shown that $40 \mathrm{mM} \mathrm{L}-\mathrm{PA}$ are almost as effective as $40 \mathrm{mM}$ proline for osmoprotection of a lysine producing C. glutamicum strain (Figures 1, 4). The improved growth in the presence of increasing salt concentrations is not due to catabolism of L-PA since C. glutamicum can use L-PA neither as carbon source nor as nitrogen source (Pérez-García et al., 2016). Rather, the external addition of L-PA is advantageous since resources for biosynthesis of L-proline for osmoprotection are not required. An osmoprotective role of L-PA has also been shown for E. coli since the addition of $1 \mathrm{mM}$ of DL-PA decreased the inhibitory growth effect of $200-700 \mathrm{mM} \mathrm{NaCl}$ in $0.2 \%$ glucose minimal medium (Gouesbet et al., 1994). When growing S. pomeroyi in a mineral salts medium containing $400 \mathrm{mM}$ $\mathrm{NaCl}$, the supplementation of $5-20 \mathrm{mM}$ of L-PA improved the growth of the microorganism (Neshich et al., 2013). In Sinorhizobium meliloti, both isomers, L-PA and D-PA have to be added for osmoprotective activity (Gouffi et al., 2000). Previously, we have developed strains for sustainable production of L-PA (Pérez-García et al., 2016, 2017a). Here, we have shown that recombinant C. glutamicum engineered for L-PA overproduction showed improved growth characteristics under hyperosmolar conditions (Figure 4). Thus, L-PA functions as osmo compatible solute not only when imported from the environment, but also when synthesized de novo. In these recombinant C. glutamicum strain synthesis is not osmostress-induced as described for certain plants. For example, in rapeseed leaf tissues, L-PA synthesis from L-lysine via the lysine-ketoglutarate reductase/saccharopine dehydrogenase pathway is osmo-dependent (Moulin et al., 2006).

Although uptake of osmo compatible solutes is important and energetically favored over their de novo synthesis, a C. glutamicum mutant devoid of the five known uptake systems for compatible solutes survived under hyperosmolar conditions (Steger et al., 2004) which has been attributed to de novo synthesis of proline, glutamine, and trehalose (Rönsch et al., 2003). The secondary carriers PutP, BetP, EctP, LcoP, and ProP differ by their substrate spectrum and substrate affinities, however, they show a degree of substrate redundancy that is typical for soil bacteria (Peter et al., 1997, 1998; Wood et al., 2001; Weinand et al., 2007). BetP is a high affinity carrier specific for betaine (Peter et al., 1997). EctP is a low affinity carrier for betaine, ectoine and proline and LcoP a low affinity carrier for betaine and ectoine, whereas the carrier ProP shows high affinity for its substrates proline and ectoine (Peter et al., 1998; Steger et al., 2004). PutP imports proline with high affinity for anabolic purposes (Peter et al., 1997). Based on differential gene expression analysis ProP was identified as possible L-PA import system in this work (Table 5). In $E$. coli various structural analogs of L-proline such as azetidine2-carboxylate, L-pipecolic acid or 5-hydroxy-L-pipecolic acid enter the cell through ProP or ProU transport systems (Gouesbet et al., 1994). The E. coli proline/glycine betaine transporter ProP shares $36.8 \%$ identical amino acids with ProP from C. glutamicum. Here, growth analysis of C. glutamicum mutants lacking proP revealed perturbed growth under hyperosmolar conditions in the absence of proP (Figure 4). Since mutants lacking proP still possess functional EctP and PutP these carriers apparently do not contribute to uptake of L-PA under the chosen conditions, and, thus, ProP may act as major L-PA import system in C. glutamicum. Detailed biochemical transport assays will have to be performed in the future to characterize L-PA uptake by ProP.

It was also shown in this work that the MSC YggB performs as a major escape valve for L-PA in C. glutamicum (Figure 2). After an osmotic downshift compatible solutes are released to the medium involving MSCs (Morbach and Krämer, 2003). In particular, the MSC YggB was described as the main export system of L-glutamate in C. glutamicum (Nakamura et al., 2007). In C. glutamicum it is known that the use of biotin limitation, penicillin treatments or surfactants alter membrane tension by inhibiting lipid or peptidoglycan synthesis which triggers conformational changes in YggB allowing L-glutamate export (Duperray et al., 1992; Gutmann et al., 1992). In addition, betaine efflux induced by osmotic downshock was reduced upon deletion of $y g g B$ (Nottebrock et al., 2003). Thus, the decreased rate of L-PA accumulation in the supernatant as consequence of $y g g B$ deletion suggests that L-PA may be exported from the C. glutamicum cell by YggB. In depth biochemical analysis is required to characterize export of L-PA by YggB.

Due to their diverse applications in drug development, food industry, skin care products and cosmetics (Graf et al., 2008; Jorge C.D. et al., 2016; Li and Gänzle, 2016) the biotechnological production of compatible solutes has gained increasing momentum recently (Sauer and Galinski, 1998; Jensen and Wendisch, 2013; Tan et al., 2016; Chen et al., 2017). This included the establishment of strains that produce and secrete compatible solutes such as ectoine, L-PA or $\alpha$-D-glucosylglycerol that are not synthesized by the wild-type strains (Ning et al., 2016; Pérez-García et al., 2017a,b; Ying et al., 2017; Roenneke et al., 2018). Production of L-PA by recombinant E. coli expressing the gene for lysine cyclodeaminase from Streptomyces hygroscopicus was established with a titer of $5.33 \mathrm{~g} \mathrm{~L}^{-1} \mathrm{~L}-\mathrm{PA}$ and a yield of $0.13 \mathrm{~g} \mathrm{~L}^{-1}$ of glucose obtained in fed-batch cultivation and a titer of $0.64 \mathrm{~g} \mathrm{~L}^{-1} \mathrm{~L}-\mathrm{PA}$ in shake flasks (Ying et al., 2017). Our previous work on establishing L-PA production in C. glutamicum led to superior values: $14.4 \mathrm{~g} \mathrm{~L}^{-1} \mathrm{~L}-\mathrm{PA}$ and a yield of $0.20 \mathrm{~g}$ $\mathrm{g}^{-1}$ in fed-batch cultivation and a titer of $3.9 \mathrm{~g} \mathrm{~L}^{-1} \mathrm{~L}-\mathrm{PA}$ in shake flasks (Pérez-García et al., 2017a). Although de novo synthesized L-PA protected C. glutamicum against high salt 
conditions, we have observed that in the presence of $200 \mathrm{mM}$ $\mathrm{NaCl}$ the L-PA titer in the supernatant was reduced from about $15 \mathrm{mM}$ (about $1.9 \mathrm{~g} \mathrm{~L}^{-1}$ ) to about half (Figure 2A, left panel). Thus, hyperosmolar conditions are not favorable for L-PA production by the C. glutamicum recombinant strains described here. However, while less L-PA was secreted under hyperosmolar conditions, more L-PA accumulated intracellularly (Figure 2A, left panel). After osmotic downshift, L-PA was released to the culture medium accumulating to about $22 \mathrm{mM}$ (about $2.8 \mathrm{~g} \mathrm{~L}^{-1}$ ) (Figure 2A, right panel). Therefore, in principle, the described C. glutamicum strains could be used in a process called "bacterial milking" (Sauer and Galinski, 1998). The Gram-negative bacterium Halomonas elongata was grown to high-cell-density (48 g cell dry weight per liter) before being exposed to alternating hyper-and hypo-osmolar conditions. Ectoine released to the hypo-osmolar medium was harvested by crossflow filtration and by this procedure $0.16 \mathrm{~g}$ of ectoine per cycle per gram cell dry weight could be produced (Sauer and Galinski, 1998). As use of high-salinity media in fermentation processes is costly and poses challenges with regard to the design and durability of bioreactors, it is generally assumed that direct fermentative production is preferred over the "bacterial milking" process. To determine if this notion holds true for the L-PA producing C. glutamicum strains described here, a head-to-head comparison of these strains operated in a fed-batch fermentation process vs. a "bacterial milking" process will have to be performed after each process has been thoroughly optimized by process intensification. In addition, strain optimization by transport engineering, as described for the production of amino acids (Nakamura et al., 2007; Blombach et al., 2009), non-proteinogenic amino acids (Jorge J.M.P. et al., 2016; Pérez-García et al., 2017a), diamines (Kind et al., 2014;

\section{REFERENCES}

Anders, S., and Huber, W. (2010). Differential expression analysis for sequence count data. Genome Biol. 11:R106. doi: 10.1186/gb-2010-11-10r106

Blombach, B., Hans, S., Bathe, B., and Eikmanns, B. J. (2009). Acetohydroxyacid synthase, a novel target for improvement of L-lysine production by Corynebacterium glutamicum. Appl. Environ. Microbiol. 75, 419-427. doi: 10. 1128/AEM.01844-08

Bolger, A. M., Lohse, M., and Usadel, B. (2014). Trimmomatic: a flexible trimmer for Illumina sequence data. Bioinforma. Oxf. Engl. 30, 2114-2120. doi: 10.1093/ bioinformatics/btu170

Bolten, C. J., Kiefer, P., Letisse, F., Portais, J.-C., and Wittmann, C. (2007). Sampling for metabolome analysis of microorganisms. Anal. Chem. 79, 3843-3849. doi: 10.1021/ac0623888

Börngen, K., Battle, A. R., Möker, N., Morbach, S., Marin, K., Martinac, B., et al. (2010). The properties and contribution of the Corynebacterium glutamicum MscS variant to fine-tuning of osmotic adaptation. Biochim. Biophys. Acta 1798, 2141-2149. doi: 10.1016/j.bbamem.2010.06.022

Bremer, E. (2000). Coping with osmotic challenges: osmoregulation through accumulation and release of compatible solutes in B. subtilis. Comp. Biochem. Physiol. A Mol. Integr. Physiol. 126:17.

Brito, L. F., Irla, M., Kalinowski, J., and Wendisch, V. F. (2017). Detailed transcriptome analysis of the plant growth promoting Paenibacillus riograndensis SBR5 by using RNA-seq technology. BMC Genomics 18:846. doi: 10.1186/s12864-017-4235-z
Nguyen et al., 2015) or organic acids (Huhn et al., 2011), may be required.

\section{DATA AVAILABILITY}

The datasets generated for this study can be found in http://www. ncbi.nlm.nih.gov/geo/, GSE122249.

\section{AUTHOR CONTRIBUTIONS}

FP-G, LB, and VW designed the study. FP-G and LB performed the experiments. FP-G, LB, and VW analyzed the data. FP-G and LB drafted the manuscript. VW finalized the manuscript. All authors read and approved the final version of the manuscript.

\section{FUNDING}

FP-G was funded by the University of Bielefeld (Bielefeld Young Researchers Fund, Germany). LB was funded by the Science without Borders program (Coordenação de Aperfeiçoamento de Pessoal de Nível Superior, Brazil). The funding agencies were not involved in the design of the study, collection, analysis, and interpretation of data and in writing the manuscript.

\section{ACKNOWLEDGMENTS}

We thank Dr. Tobias Busche and Prof. Dr. Jörn Kalinowski from the technology platform Genomics of CeBiTec for the kind assistance with the preparation and sequencing of the cDNA libraries.

Chen, R., Zhu, L., Lv, L., Yao, S., Li, B., and Qian, J. (2017). Optimization of the extraction and purification of the compatible solute ectoine from Halomonas elongata in the laboratory experiment of a commercial production project. World J. Microbiol. Biotechnol. 33:116. doi: 10.1007/s11274-017-2281-y

Crooks, G. E., Hon, G., Chandonia, J.-M., and Brenner, S. E. (2004). WebLogo: a sequence logo generator. Genome Res. 14, 1188-1190. doi: 10.1101/gr.849004

Czech, L., Hermann, L., Stöveken, N., Richter, A. A., Höppner, A., Smits, S. H. J., et al. (2018). Role of the extremolytes ectoine and hydroxyectoine as stress protectants and nutrients: genetics, phylogenomics, biochemistry, and structural analysis. Genes 9:E177. doi: 10.3390/genes9040177

da Costa, M. S., Santos, H., and Galinski, E. A. (1998). An overview of the role and diversity of compatible solutes in bacteria and archaea. Adv. Biochem. Eng. Biotechnol. 61, 117-153.

Duperray, F., Jezequel, D., Ghazi, A., Letellier, L., and Shechter, E. (1992). Excretion of glutamate from Corynebacterium glutamicum triggered by amine surfactants. Biochim. Biophys. Acta Biomembr. 1103, 250-258. doi: 10.1016/0005-2736(92) 90094-3

Eggeling, L., and Bott, M. (2005). Handbook of Corynebacterium glutamicum. Boca Raton, FL: CRC Press.

Farwick, M., Siewe, R. M., and Krämer, R. (1995). Glycine betaine uptake after hyperosmotic shift in Corynebacterium glutamicum. J. Bacteriol. 177, 4690-4695.

Frings, E., Kunte, H. J., and Galinski, E. A. (1993). Compatible solutes in representatives of the genera Brevibacterium and Corynebacterium: occurrence of tetrahydropyrimidines and glutamine. FEMS Microbiol. Lett. 109, 25-32. doi: 10.1111/j.1574-6968.1993.tb06138.x 
Gibson, D. G. (2011). Enzymatic assembly of overlapping DNA fragments. Methods Enzymol. 498, 349-361. doi: 10.1016/B978-0-12-385120-8.00015-2

Gouesbet, G., Blanco, C., Hamelin, J., and Bernard, T. (1992). Osmotic adjustment in Brevibacterium ammoniagenes: pipecolic acid accumulation at elevated osmolalities. Microbiology 138, 959-965. doi: 10.1099/00221287-138-5-959

Gouesbet, G., Jebbar, M., Talibart, R., Bernard, T., and Blanco, C. (1994). Pipecolic acid is an osmoprotectant for Escherichia coli taken up by the general osmoporters ProU and ProP. Microbiol. Read. Engl. 140(Pt 9), 2415-2422. doi: 10.1099/13500872-140-9-2415

Gouffi, K., Bernard, T., and Blanco, C. (2000). Osmoprotection by pipecolic acid in Sinorhizobium meliloti: specific effects of $\mathrm{d}$ and 1 isomers. Appl. Environ. Microbiol. 66, 2358-2364.

Graf, R., Anzali, S., Buenger, J., Pfluecker, F., and Driller, H. (2008). The multifunctional role of ectoine as a natural cell protectant. Clin. Dermatol. 26, 326-333. doi: 10.1016/j.clindermatol.2008.01.002

Guillouet, S., and Engasser, J. M. (1995). Sodium and proline accumulation in Corynebacterium glutamicum as a response to an osmotic saline upshock. Appl. Microbiol. Biotechnol. 43, 315-320. doi: 10.1007/BF00172831

Gutmann, M., Hoischen, C., and Krämer, R. (1992). Carrier-mediated glutamate secretion by Corynebacterium glutamicum under biotin limitation. Biochim. Biophys. Acta 1112, 115-123.

Hanahan, D. (1983). Studies on transformation of Escherichia coli with plasmids. J. Mol. Biol. 166, 557-580.

Hilker, R., Stadermann, K. B., Doppmeier, D., Kalinowski, J., Stoye, J., Straube, J., et al. (2014). ReadXplorer-visualization and analysis of mapped sequences. Bioinformatics 30, 2247-2254. doi: 10.1093/bioinformatics/btu205

Hoffmann, T., and Bremer, E. (2017). Guardians in a stressful world: the Opu family of compatible solute transporters from Bacillus subtilis. Biol. Chem. 398, 193-214. doi: 10.1515/hsz-2016-0265

Huhn, S., Jolkver, E., Krämer, R., and Marin, K. (2011). Identification of the membrane protein SucE and its role in succinate transport in Corynebacterium glutamicum. Appl. Microbiol. Biotechnol. 89, 327-335. doi: 10.1007/s00253-0102855-1

Irla, M., Neshat, A., Brautaset, T., Rückert, C., Kalinowski, J., and Wendisch, V. F. (2015). Transcriptome analysis of thermophilic methylotrophic Bacillus methanolicus MGA3 using RNA-sequencing provides detailed insights into its previously uncharted transcriptional landscape. BMC Genomics 16:73. doi: 10.1186/s12864-015-1239-4

Jensen, J. V. K., and Wendisch, V. F. (2013). Ornithine cyclodeaminase-based proline production by Corynebacterium glutamicum. Microb. Cell Fact. 12:63. doi: $10.1186 / 1475-2859-12-63$

Jorge, C. D., Borges, N., Bagyan, I., Bilstein, A., and Santos, H. (2016). Potential applications of stress solutes from extremophiles in protein folding diseases and healthcare. Extremophiles 20, 251-259. doi: 10.1007/s00792-016-0828-8

Jorge, J. M. P., Nguyen, A. Q. D., Pérez-García, F., Kind, S., and Wendisch, V. F. (2016). Improved fermentative production of gamma-aminobutyric acid via the putrescine route: systems metabolic engineering for production from glucose, amino sugars and xylose. Biotechnol. Bioeng. 114, 862-873. doi: 10.1002/bit. 26211

Jorge, J. M. P., Pérez-García, F., and Wendisch, V. F. (2017). A new metabolic route for the fermentative production of 5-aminovalerate from glucose and alternative carbon sources. Bioresour. Technol. 245, 1701-1709. doi: 10.1016/ j.biortech.2017.04.108

Kalinowski, J., Bathe, B., Bartels, D., Bischoff, N., Bott, M., Burkovski, A., et al. (2003). The complete Corynebacterium glutamicum ATCC 13032 genome sequence and its impact on the production of L-aspartate-derived amino acids and vitamins. J. Biotechnol. 104, 5-25.

Kempf, B., and Bremer, E. (1998). Uptake and synthesis of compatible solutes as microbial stress responses to high-osmolality environments. Arch. Microbiol. $170,319-330$

Kind, S., Jeong, W. K., Schröder, H., and Wittmann, C. (2010). Systems-wide metabolic pathway engineering in Corynebacterium glutamicum for bio-based production of diaminopentane. Metab. Eng. 12, 341-351. doi: 10.1016/j.ymben. 2010.03.005

Kind, S., Neubauer, S., Becker, J., Yamamoto, M., Völkert, M., Abendroth, G., et al. (2014). From zero to hero - production of bio-based nylon from renewable resources using engineered Corynebacterium glutamicum. Metab. Eng. 25, 113-123. doi: 10.1016/j.ymben.2014.05.007
Klingenberg, M., and Pfaff, E. (1967). “Means or terminating reactions," in Methods of Enzymology, Vol. X, eds R. W. Estabrook and M. R. Pullamnn (New York, NY: Academic press), 680-684.

Langmead, B., Trapnell, C., Pop, M., and Salzberg, S. L. (2009). Ultrafast and memory-efficient alignment of short DNA sequences to the human genome. Genome Biol. 10:R25. doi: 10.1186/gb-2009-10-3-r25

Li, H., and Gänzle, M. (2016). Some like it hot: heat resistance of Escherichia coli in food. Front. Microbiol. 7:1763. doi: 10.3389/fmicb.2016.01763

Lubitz, D., and Wendisch, V. F. (2016). Ciprofloxacin triggered glutamate production by Corynebacterium glutamicum. BMC Microbiol. 16:235. doi: 10. 1186/s12866-016-0857-6

Mentz, A., Neshat, A., Pfeifer-Sancar, K., Pühler, A., Rückert, C., and Kalinowski, J. (2013). Comprehensive discovery and characterization of small RNAs in Corynebacterium glutamicum ATCC 13032. BMC Genomics 14:714. doi: 10. 1186/1471-2164-14-714

Mimitsuka, T., Sawai, H., Hatsu, M., and Yamada, K. (2007). Metabolic engineering of Corynebacterium glutamicum for cadaverine fermentation. Biosci. Biotechnol. Biochem. 71, 2130-2135. doi: 10.1271/bbb.60699

Morbach, S., and Krämer, R. (2003). Impact of transport processes in the osmotic response of Corynebacterium glutamicum. J. Biotechnol. 104, 69-75.

Moulin, M., Deleu, C., Larher, F., and Bouchereau, A. (2006). The lysineketoglutarate reductase-saccharopine dehydrogenase is involved in the osmoinduced synthesis of pipecolic acid in rapeseed leaf tissues. Plant Physiol. Biochem. 44, 474-482. doi: 10.1016/j.plaphy.2006.08.005

Nakamura, J., Hirano, S., Ito, H., and Wachi, M. (2007). Mutations of the Corynebacterium glutamicum NCgl1221 gene, encoding a mechanosensitive channel homolog, induce L-glutamic acid production. Appl. Environ. Microbiol. 73, 4491-4498. doi: 10.1128/AEM.02446-06

Naville, M., Ghuillot-Gaudeffroy, A., Marchais, A., and Gautheret, D. (2011). ARNold: a web tool for the prediction of Rho-independent transcription terminators. RNA Biol. 8, 11-13.

Neshich, I. A. P., Kiyota, E., and Arruda, P. (2013). Genome-wide analysis of lysine catabolism in bacteria reveals new connections with osmotic stress resistance. ISME J. 7, 2400-2410. doi: 10.1038/ismej.2013.123

Nguyen, A. Q. D., Schneider, J., Reddy, G. K., and Wendisch, V. F. (2015). Fermentative production of the diamine putrescine: system metabolic engineering of Corynebacterium glutamicum. Metabolites 5, 211-231. doi: 10. 3390/metabo5020211

Ning, Y., Wu, X., Zhang, C., Xu, Q., Chen, N., and Xie, X. (2016). Pathway construction and metabolic engineering for fermentative production of ectoine in Escherichia coli. Metab. Eng. 36, 10-18. doi: 10.1016/j.ymben.2016.02.013

Nottebrock, D., Meyer, U., Krämer, R., and Morbach, S. (2003). Molecular and biochemical characterization of mechanosensitive channels in Corynebacterium glutamicum. FEMS Microbiol. Lett. 218, 305-309.

Pérez-García, F., Max Risse, J., Friehs, K., and Wendisch, V. F. (2017a). Fermentative production of L-pipecolic acid from glucose and alternative carbon sources. Biotechnol. J. 12:1600646. doi: 10.1002/biot.201600646

Pérez-García, F., Ziert, C., Risse, J. M., and Wendisch, V. F. (2017b). Improved fermentative production of the compatible solute ectoine by Corynebacterium glutamicum from glucose and alternative carbon sources. J. Biotechnol. 258, 59-68. doi: 10.1016/j.jbiotec.2017.04.039

Pérez-García, F., Peters-Wendisch, P., and Wendisch, V. F. (2016). Engineering Corynebacterium glutamicum for fast production of L-lysine and L-pipecolic acid. Appl. Microbiol. Biotechnol. 100, 8075-8090. doi: 10.1007/s00253-0167682-6

Peter, H., Bader, A., Burkovski, A., Lambert, C., and Krämer, R. (1997). Isolation of the putP gene of Corynebacterium glutamicum and characterization of a low-affinity uptake system for compatible solutes. Arch. Microbiol. 168, 143-151.

Peter, H., Weil, B., Burkovski, A., Krämer, R., and Morbach, S. (1998). Corynebacterium glutamicum is equipped with four secondary carriers for compatible solutes: identification, sequencing, and characterization of the proline/ectoine uptake system, ProP, and the ectoine/proline/glycine betaine carrier, EctP. J. Bacteriol. 180, 6005-6012.

Peters-Wendisch, P. G., Schiel, B., Wendisch, V. F., Katsoulidis, E., Möckel, B., Sahm, H., et al. (2001). Pyruvate carboxylase is a major bottleneck for glutamate and lysine production by Corynebacterium glutamicum. J. Mol. Microbiol. Biotechnol. 3, 295-300. 
Roenneke, B., Rosenfeldt, N., Derya, S. M., Novak, J. F., Marin, K., Krämer, R., et al. (2018). Production of the compatible solute $\alpha$-D-glucosylglycerol by metabolically engineered Corynebacterium glutamicum. Microb. Cell Fact. 17:94. doi: 10.1186/s12934-018-0939-2

Rönsch, H., Krämer, R., and Morbach, S. (2003). Impact of osmotic stress on volume regulation, cytoplasmic solute composition and lysine production in Corynebacterium glutamicum MH20-22B. J. Biotechnol. 104, 87-97.

Ruffert, S., Berrier, C., Krämer, R., and Ghazi, A. (1999). Identification of mechanosensitive ion channels in the cytoplasmic membrane of Corynebacterium glutamicum. J. Bacteriol. 181, 1673-1676.

Ruffert, S., Lambert, C., Peter, H., Wendisch, V. F., and Krämer, R. (1997). Efflux of compatible solutes in Corynebacterium glutamicum mediated by osmoregulated channel activity. Eur. J. Biochem. FEBS 247, 572-580.

Sajjad, W., Qadir, S., Ahmad, M., Rafiq, M., Hasan, F., Tehan, R., et al. (2018). Ectoine: a compatible solute in radio-halophilic Stenotrophomonas sp. WMALM19 strain to prevent ultraviolet-induced protein damage. J. Appl. Microbiol. 125, 457-467. doi: 10.1111/jam.13903

Sauer, T., and Galinski, E. A. (1998). Bacterial milking: a novel bioprocess for production of compatible solutes. Biotechnol. Bioeng. 57, 306-313.

Schäfer, A., Tauch, A., Jäger, W., Kalinowski, J., Thierbach, G., and Pühler, A. (1994). Small mobilizable multi-purpose cloning vectors derived from the Escherichia coli plasmids pK18 and pK19: selection of defined deletions in the chromosome of Corynebacterium glutamicum. Gene 145, 69-73.

Schaffer, S., Weil, B., Nguyen, V. D., Dongmann, G., Günther, K., Nickolaus, M., et al. (2001). A high-resolution reference map for cytoplasmic and membraneassociated proteins of Corynebacterium glutamicum. Electrophoresis 22, 4404-4422.

Schneider, J., and Wendisch, V. F. (2010). Putrescine production by engineered Corynebacterium glutamicum. Appl. Microbiol. Biotechnol. 88, 859-868. doi: 10.1007/s00253-010-2778-x

Simon, R., Priefer, U., and Pühler, A. (1983). A broad host range mobilization system for in vivo genetic engineering: transposon mutagenesis in gram negative bacteria. Nat. Biotechnol. 1, 784-791. doi: 10.1038/nbt1183-784

Skjerdal, O. T., Sletta, H., Flenstad, S. G., Josefsen, K. D., Levine, D. W., and Ellingsen, T. E. (1996). Changes in intracellular composition in response to hyperosmotic stress of $\mathrm{NaCl}$, sucrose or glutamic acid in Brevibacterium lactofermentum and Corynebacterium glutamicum. Appl. Microbiol. Biotechnol. 44, 635-642. doi: 10.1007/BF00172497

Stansen, C., Uy, D., Delaunay, S., Eggeling, L., Goergen, J. L., and Wendisch, V. F. (2005). Characterization of a Corynebacterium glutamicum lactate utilization operon induced during temperature-triggered glutamate production. Appl. Environ. Microbiol. 71, 5920-5928. doi: 10.1128/AEM.71.10.5920-5928.2005
Steger, R., Weinand, M., Krämer, R., and Morbach, S. (2004). LcoP, an osmoregulated betaine/ectoine uptake system from Corynebacterium glutamicum. FEBS Lett. 573, 155-160. doi: 10.1016/j.febslet.2004.07.067

Sun, Y., Guo, W., Wang, F., Peng, F., Yang, Y., Dai, X., et al. (2016). Transcriptome and multivariable data analysis of Corynebacterium glutamicum under different dissolved oxygen conditions in bioreactors. PLoS One 11:e0167156. doi: 10. 1371/journal.pone.0167156

Tan, X., Luo, Q., and Lu, X. (2016). Biosynthesis, biotechnological production, and applications of glucosylglycerols. Appl. Microbiol. Biotechnol. 100, 6131-6139. doi: 10.1007/s00253-016-7608-3

Tribelli, P. M., and López, N. I. (2018). Reporting key features in cold-adapted bacteria. Life 8:E8. doi: 10.3390/life8010008

Vranova, V., Lojkova, L., Rejsek, K., and Formanek, P. (2013). Significance of the natural occurrence of L- versus D-pipecolic acid: a review. Chirality 25, 823-831. doi: 10.1002/chir.22237

Weinand, M., Krämer, R., and Morbach, S. (2007). Characterization of compatible solute transporter multiplicity in Corynebacterium glutamicum. Appl. Microbiol. Biotechnol. 76, 701-708. doi: 10.1007/s00253-007-0938-4

Wolf, A., Krämer, R., and Morbach, S. (2003). Three pathways for trehalose metabolism in Corynebacterium glutamicum ATCC13032 and their significance in response to osmotic stress. Mol. Microbiol. 49, 1119-1134.

Wood, J. M. (1999). Osmosensing by bacteria: signals and membrane-based sensors. Microbiol. Mol. Biol. Rev. 63, 230-262.

Wood, J. M., Bremer, E., Csonka, L. N., Kraemer, R., Poolman, B., van der Heide, T., et al. (2001). Osmosensing and osmoregulatory compatible solute accumulation by bacteria. Comp. Biochem. Physiol. A. Mol. Integr. Physiol. 130, 437-460.

Ying, H., Tao, S., Wang, J., Ma, W., Chen, K., Wang, X., et al. (2017). Expanding metabolic pathway for de novo biosynthesis of the chiral pharmaceutical intermediate L-pipecolic acid in Escherichia coli. Microb. Cell Fact. 16:52. doi: 10.1186/s12934-017-0666-0

Conflict of Interest Statement: The authors declare that the research was conducted in the absence of any commercial or financial relationships that could be construed as a potential conflict of interest.

Copyright (c) 2019 Pérez-García, Brito and Wendisch. This is an open-access article distributed under the terms of the Creative Commons Attribution License (CC BY). The use, distribution or reproduction in other forums is permitted, provided the original author(s) and the copyright owner(s) are credited and that the original publication in this journal is cited, in accordance with accepted academic practice. No use, distribution or reproduction is permitted which does not comply with these terms. 